\title{
THE STUDY OF SPECIES AND THE STUDY OF CELLS.
}

\author{
BY JAMES HENRY EMERTON, BOSTON, MASS.
}

\section{[Annual address of the retiring president of the Cambridge Entomological Club, I3 January 1888.]}

During the last few years the study of species has become less and less fashionable among naturalists. New species are still described and old ones better defined. The changes which animals pass through as they grow up are better understood and their habits and distribution better known and explained but all this work is carried on in the face of the opinion of a large body of our most active naturalists that it is not the most proper kind of work for a naturalist to do and might as well be left undone. For this reason many students have felt that they could make no investigations of any value without a laboratory and complicated apparatus of the latest kind and others who have begun valuable sysetmatic studies have felt called upon to waste what they had done and begin again a new kind of study.

This state of things is of special interest to entomologists. The great number of species of insects makes it important that there should always be men who make it their special work to know the species of large groups and who are able to make use of new discoveries in improving their classification and any prejudice that prevents the best young naturalists from beginning early the study of species and getting the knowledge and practice it needs, is one that entomologists above all others should do their best to discourage.

It is hard for us to realize that twentyfive or thirty years ago most naturalists believed that species could not be explained and were for all practical purposes the bottom facts of natural history. The sudden change of opinion on this subject has naturally led to a compara. tive neglect of the study of species.

At the same time the improvements of microscopes and improved methods of dissection by which each cell in an animal can be separately examined have opened a new field of study which has clrawn attention away from older ones.

A student beginning his studies naturally follows that line which is most popular or most novel at the time. He sees the latest books filled with discoveries in that direction, his teachers are helping to make those discoveries and he sees in doing the same thing the best prospect of success in his profession.

I would not undervalue in any way the microscopic anatomical work now so popular with students, but only the prejudice which leads them to believe that it is something different from and superior to the study and classification of whole animals.

The study of species has for its object to improve their classification, that is to measure their resemblances and 
differences and in this way try to explain why they differ from each other and why some kinds exist instead of others that might have existed.

The study of microscopic anatomy attempts the same thing with smaller objects. It compares cells together and classifies them into layers and tissues and so tries to explain the cause of their differences and why they combine together some into one organ and some into another.

In the study of species there is use for all the facts that can be found. It is true our classifications of most animals is based on a very superficial knowledge of them but this is because the number of animals is so great that there has not been time to know more. There is no prospect of everything being known about any one animal and our classifications and theories must be made to suit the facts as they are and then improved as knowledge increases.

It has often been urged against the study of species that is largely a study of names, and students have turned to histology or embryology hoping to avoid this and accomplish more with the same labor. This may have been possible once but any embryological or histological book of the present time has as large a part devoted to the meanings of words and interpretations of the descriptions of other writers on the same subject as any book on classification, nor is there any reason to believe that the proportion of space thus devoted to synonymy will decrease.

The classification of species is largely based on specimens which are kept in museums more or less public and it is often possible for persons interested to compare them with what has been written about them and the importance of preserving such type specimens is generally recognized.

The type specimens of microscopic studies are generally kept by individual students and are small and easily destroyed so that the facilities for comparison are small.

Thus the mistakes of systematic natural history are more easily seen and the difference between good and bad work understood by a large number of persons while the mistakes of microscopic observations are hard to find and so supposed to be rare.

The students of the present day can therefore go on describing new cells with the same freedom with which those of the past generation described species leaving to those that come after them to correct and explain what they have written. With increase in the number of students this advantage is passing away and the histologist will soon have to spend as much labor in identifying what he finds as the student of species.

When the attractions of a new study are gone we shall see that, except in the size of the object studied these two lines of work differ but little and one is as likely to gather valuable facts and new theories as the other and that in either field the value of the work depends only on the care and skill with which it is done. 

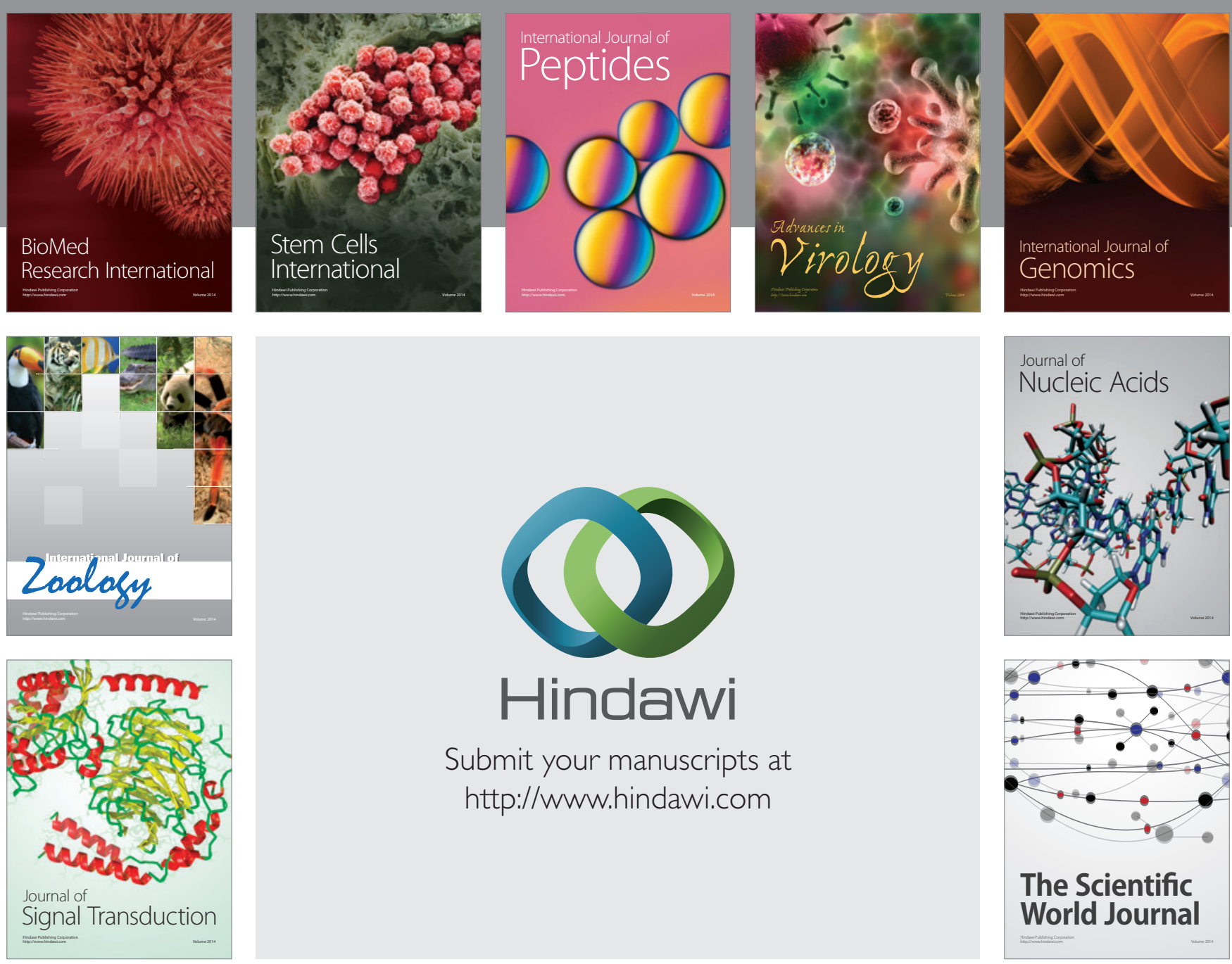

Submit your manuscripts at

http://www.hindawi.com
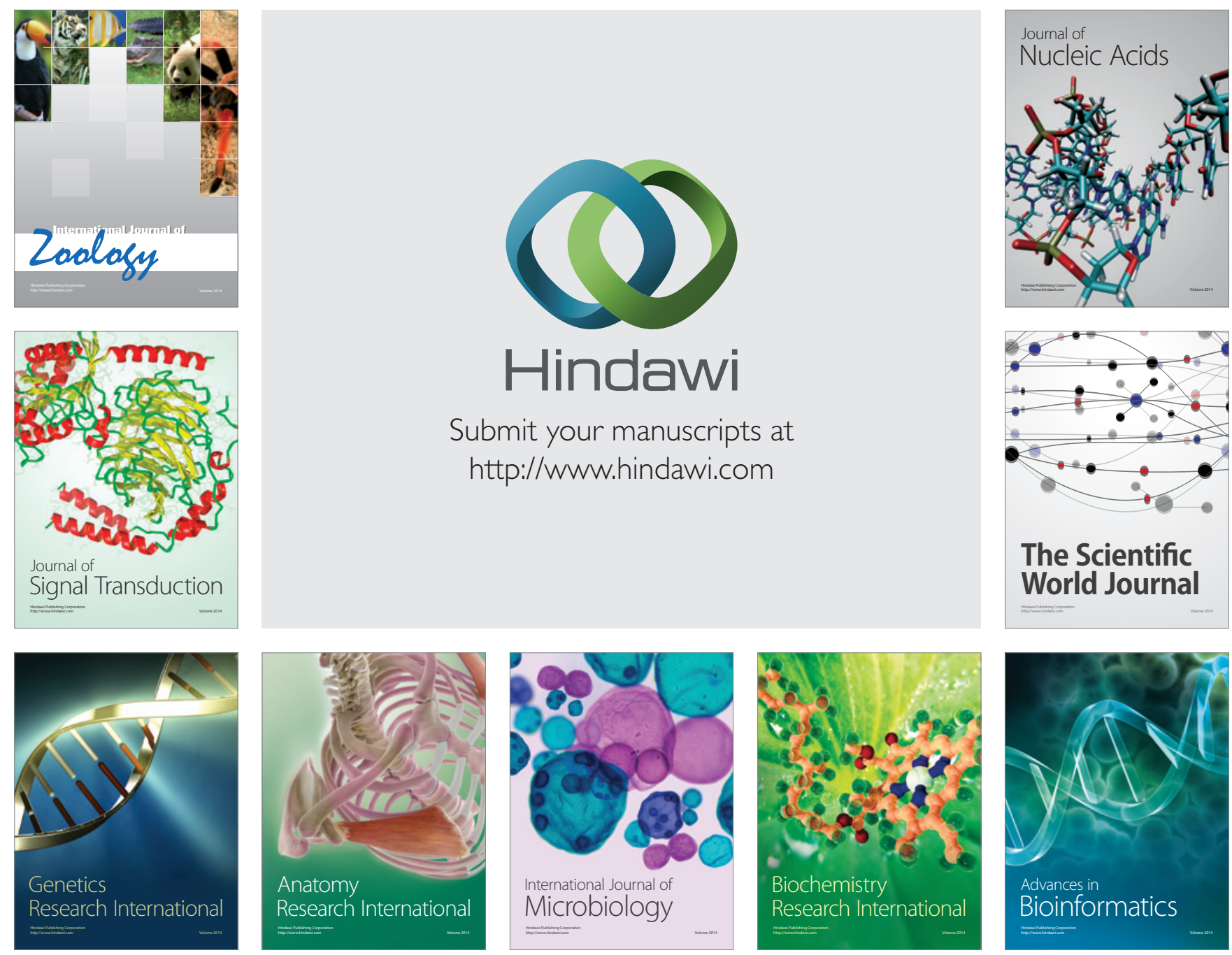

The Scientific World Journal
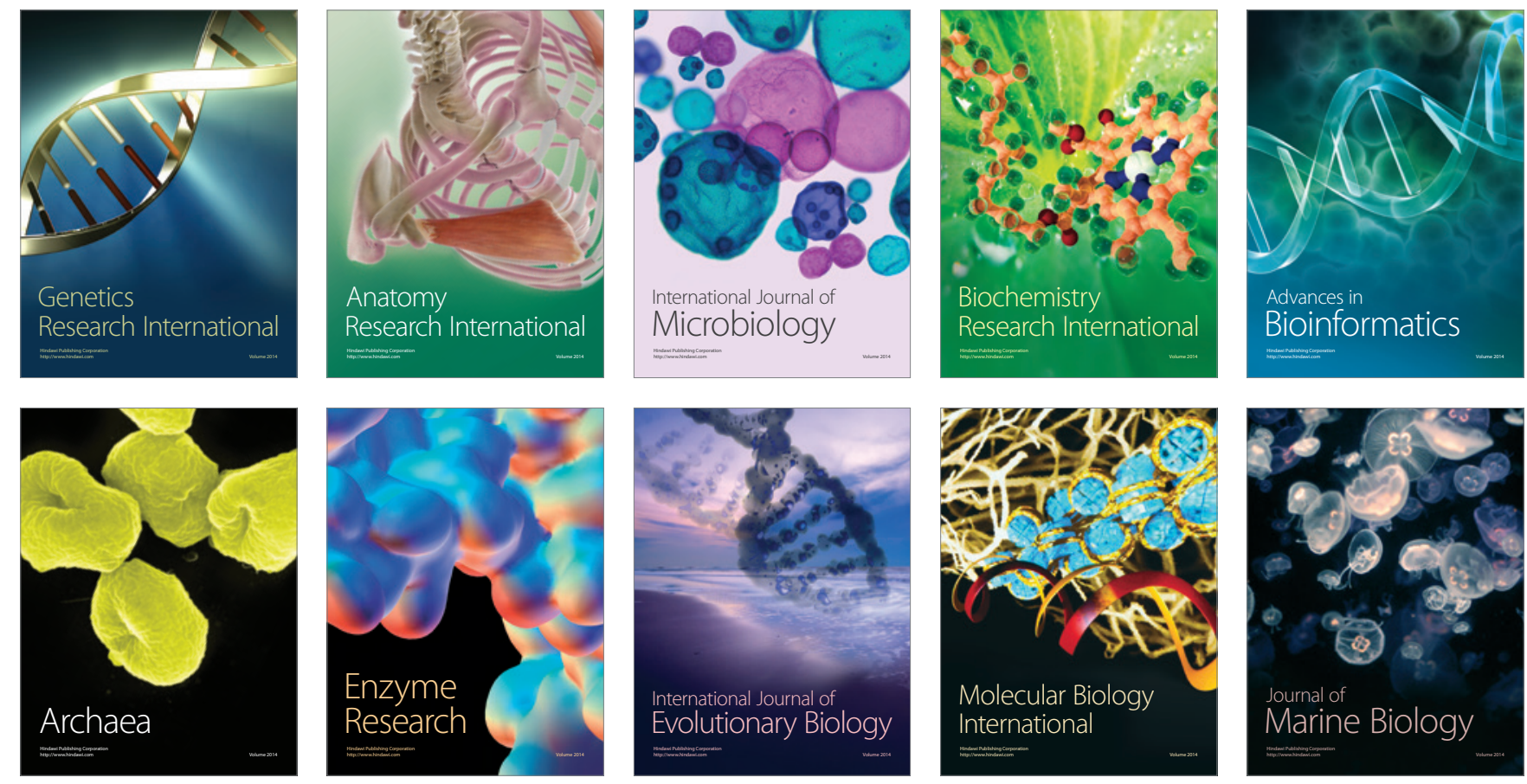